\title{
Widespread Cardiac and Vasomotor Autonomic Dysfunction in Non-Val30Met Hereditary Transthyretin Amyloidosis
}

\author{
Haruki Koike ${ }^{1}$, Tomohiko Nakamura ${ }^{1}$, Ryoji Nishi ${ }^{1}$, Shohei Ikeda ${ }^{1}$, Yuichi Kawagashira ${ }^{1}$, \\ Masahiro Iijima $^{1}$, Masahisa Katsuno ${ }^{1}$ and Gen Sobue ${ }^{1,2}$
}

\begin{abstract}
:
Objective The autonomic functions of hereditary transthyretin (ATTRm) amyloidosis, traditionally referred to as familial amyloid polyneuropathy, have primarily been investigated in patients with Val30Met mutations, and information regarding non-Val30Met patients is scarce. The aim of this study was to systematically investigate the cardiac and peripheral vasomotor autonomic functions in non-Val30Met patients.

Methods The coefficient of variation of R-R intervals (CVR-R), responses to the Valsalva manoeuvre, head-up tilt test results, noradrenaline infusion test results, and the (123)I-metaiodobenzylguanidine (MIBG) uptake on myocardial scintigraphy were assessed in five patients. The predominant manifestations were neuropathy in three patients (Val94Gly, Val71Ala, and Pro24Ser), cardiomyopathy in one (Thr60Ala), and oculoleptomeningeal involvement in one (Tyr114Cys).

Results Although one patient with predominant cardiomyopathy did not manifest orthostatic hypotension during the head-up tilt test, the CVR-R, responses to the Valsalva manoeuvre, and myocardial MIBG uptake indicated the presence of cardiac sympathetic and parasympathetic dysfunction in all patients. The total peripheral resistance at $60^{\circ}$ tilt did not increase from the baseline values in any of the examined patients. An infusion of low-dose noradrenaline induced an increase in the systolic blood pressure, except in one patient with mild neuropathy.

Conclusion Cardiac and peripheral vasomotor autonomic dysfunctions were prevalent in non-Val30Met patients, irrespective of their phenotype, suggesting a common pathology of autonomic involvement. However, the vasoconstrictor function was preserved, even in a patient with advanced neuropathy.
\end{abstract}

Key words: amyloid, familial amyloid polyneuropathy, FAP, neuropathy, resistance vessels, transthyretin

(Intern Med 57: 3365-3370, 2018)

(DOI: 10.2169/internalmedicine.1113-18)

\section{Introduction}

Hereditary transthyretin (ATTRm) amyloidosis, traditionally referred to as familial amyloid polyneuropathy, is a disease in which the systemic deposition of amyloidogenic mutant transthyretin causes multi-organ failure. Although Val30Met (p.Val50Met) is the most common mutation in ATTRm amyloidosis, over 130 other mutations have been reported to date (1). Recent studies have revealed that certain types of non-Val30Met patients are more frequent than Val30Met patients in some countries (2-4). The phenotypes associated with non-Val30Met ATTRm amyloidosis are highly diverse and primarily include neuropathy, cardiomyopathy, or oculoleptomeningeal involvement (5). In addition, the neuropathic features of non-Val30Met patients vary depending on the corresponding mutations $(6,7)$. Autonomic manifestations are frequently reported in nonVal30Met patients $(5,7)$. Among these, orthostatic symptoms resulting from cardiovascular autonomic dysfunctions significantly disturb daily life (8). Cardiovascular autonomic functions have primarily been investigated in patients with Val30Met mutations (9-14). In contrast, information regarding systematic cardiovascular autonomic functions in non-

${ }^{1}$ Department of Neurology, Nagoya University Graduate School of Medicine, Japan and ${ }^{2}$ Research Division of Dementia and Neurodegenerative Disease, Nagoya University Graduate School of Medicine, Japan

Received: March 4, 2018; Accepted: April 22, 2018; Advance Publication by J-STAGE: July 6, 2018

Correspondence to Dr. Haruki Koike, koike-haruki@med.nagoya-u.ac.jp 
Table 1. Clinical Characteristics.

\begin{tabular}{|c|c|c|c|c|c|c|c|c|c|c|c|c|}
\hline \multirow[b]{2}{*}{ Case } & \multirow[b]{2}{*}{ Mutation } & \multirow[b]{2}{*}{$\begin{array}{l}\text { Predominant } \\
\text { phenotype }\end{array}$} & \multirow[b]{2}{*}{ Sex } & \multirow[b]{2}{*}{$\begin{array}{c}\text { Age at } \\
\text { examination } \\
\text { (years) }\end{array}$} & \multirow[b]{2}{*}{$\begin{array}{c}\text { Duration of } \\
\text { neuropathy } \\
\text { (years) }\end{array}$} & \multirow[b]{2}{*}{$\begin{array}{c}\text { Initial } \\
\text { symptom of } \\
\text { neuropathy }\end{array}$} & \multirow[b]{2}{*}{$\begin{array}{l}\text { Modified } \\
\text { Rankin } \\
\text { scale* }\end{array}$} & \multicolumn{5}{|c|}{ Cardiac findings } \\
\hline & & & & & & & & $\begin{array}{c}\mathrm{CTR} * * \\
(\%)\end{array}$ & $\begin{array}{c}\mathrm{EF} * * * \\
(\%)\end{array}$ & $\begin{array}{l}\text { IVS*** } \\
\text { thickness } \\
(\mathrm{mm})\end{array}$ & $\mathrm{E} / \mathrm{e}^{\prime}$ & $\begin{array}{c}\text { Plasma } \\
\text { BNP } \\
(\mathrm{pg} / \mathrm{mL})\end{array}$ \\
\hline 1 & Val94Gly & Neuropathy & $\mathrm{F}$ & 51 & 2 & $P$ in $U E$ & 2 & 51 & 61 & 11.6 & 11.9 & 56.1 \\
\hline 2 & Val71Ala & Neuropathy & $\mathrm{F}$ & 35 & 4 & $\mathrm{P}$ in $\mathrm{LE}$ & 4 & 38 & 74 & 7.5 & ND & ND \\
\hline 3 & Pro24Ser & Neuropathy & M & 75 & 5 & $P$ in $L E$ & 2 & 44 & 62 & 13.1 & 14.6 & 56.7 \\
\hline 4 & Thr60Ala & Cardiomyopathy & M & 64 & 1 & $P$ in $L E$ & 1 & 52 & 39 & 15.2 & 21.1 & $89.2 * * * *$ \\
\hline 5 & Tyr114Cys & $\begin{array}{l}\text { Oculolepto- } \\
\text { meningeal }\end{array}$ & M & 43 & 4 & $P$ in $L E$ & 3 & 36 & 66 & 9.5 & 9.9 & 55.8 \\
\hline
\end{tabular}

CTR: cardiothoracic ratio, EF: ejection fraction, IVS: interventricular septum, LE: lower extremities, ND: not determined, P: paraesthesia or pain, UE: upper extremities

*According to a previous report (15): $0=$ no symptoms at all; $1=$ no significant disability despite the presence of symptoms, demonstrated as the ability to perform all typical duties and activities; $2=$ slight disability, demonstrated as the inability to perform all previous activities but the ability to perform self-care without assistance; $3=$ moderate disability, demonstrated as requiring some help but being able to walk without assistance; $4=$ moderately severe disability, demonstrated as the inability to walk without assistance and to attend to bodily needs without assistance; and 5=severe disability, demonstrated as being bedridden and incontinent and requiring constant nursing care and attention.

**Assessed by chest X-ray

***Assessed by two-dimensional and M-mode echocardiography

$* * * *$ Diuretic agents were administered.

The normal values for CTR, EF, IVS thickness, E/e' and plasma BNP are $\leq 50 \%,>60 \%, \leq 11 \mathrm{~mm}, \leq 8$, and $\leq 20 \mathrm{pg} / \mathrm{mL}$, respectively.

Val30Met patients remains scarce.

In this study, we systematically assessed the cardiac and peripheral vasomotor autonomic functions in five nonVal30Met (Val94Gly, Val71Ala, Pro24Ser, Thr60Ala, and Tyr114Cys) ATTRm amyloidosis patients by analysing the coefficient of variation of R-R intervals (CVR-R), responses to the Valsalva manoeuvre, head-up tilt test results, noradrenaline infusion test results, and (123) Imetaiodobenzylguanidine (MIBG) uptake on myocardial scintigraphy.

\section{Materials and Methods}

\section{Patients}

We examined the cardiac and vasomotor autonomic functions in five ATTRm amyloidosis patients with non-Val30 Met (Val94Gly, Val71Ala, Pro24Ser, Thr60Ala, and Tyr114Cys) mutations who were referred to the Nagoya University Graduate School of Medicine (Table 1). All patients except one were from Japan; Patient 2 (Val71Ala) was an immigrant from Brazil. The severity of neuropathy was assessed by the modified Rankin Scale at the time of the autonomic function tests (15). Informed consent was obtained, and this study was approved by the Ethics Committees of Nagoya University Graduate School of Medicine and conformed to the Ethical Guidelines for Medical and Health Research Involving Human Subjects endorsed by the Japanese government.

\section{Cardiovascular autonomic function tests}

Cardiovascular autonomic function tests were performed consecutively in the morning as previously de- scribed (14, 16-19). All patients discontinued any drugs that might influence the cardiovascular system for at least 12 hours prior to the study and fasted in the morning. Electrocardiogram recordings were collected in the supine position with normal breathing to analyse the CVR-R using a standard device after 5 minutes of bed rest (14). We then performed the Valsalva manoeuvre (19); the intrathoracic pressure was kept at $40 \mathrm{mmHg}$ for 15 seconds by blowing through a mouthpiece connected to a mercury manometer (i. e. Valsalva strain). The changes in systolic blood pressure and R-R intervals were divided into four phases. We defined a time frame of 30 seconds from the initiation of the Valsalva strain to determine the maximum systolic blood pressure in phase IV because some patients may not exhibit the overshoot of systolic blood pressure normally observed in phase IV (19). The Valsalva ratio was calculated as the maximum R-R interval in phase IV divided by the minimum $\mathrm{R}-\mathrm{R}$ interval in phase II. The pressure difference between the baseline systolic blood pressure and the maximum systolic blood pressure in phase IV was defined as the Valsalva test.

Next, we conducted the head-up tilt test. After resting in a supine position for at least 5 minutes, subjects were tilted up to $60^{\circ}$ in a stepwise manner $\left(20^{\circ}, 40^{\circ}\right.$, and $60^{\circ}$ for $5 \mathrm{~min}$ utes each) to assess the change in systolic blood pressure at $60^{\circ}$ compared with the baseline level in the supine position. Cardiovascular recordings were performed using a noninvasive monitoring device (Task Force Monitor, CNSystems, Medizintechnik, Graz, Austria) during the head-up tilt test to examine the total peripheral resistance $(18,20)$. Total peripheral resistance was calculated using the cardiac output, mean arterial pressure, and central venous pressure $(18,20)$. Cardiac parameters were obtained at every beat from imped- 
Table 2. Autonomic Symptoms.

\begin{tabular}{ccccccc}
\hline \multirow{2}{*}{ Case } & $\begin{array}{c}\text { Nausea } \\
\text { /vomiting }\end{array}$ & Diarrhoea & Constipation & \multicolumn{2}{c}{ Orthostatic intolerance } & Dysuria \\
\cline { 5 - 6 } 1 & - & + & - & Dizziness & Syncope & \\
2 & - & - & + & + & $-*$ & - \\
3 & - & - & - & + & - & - \\
4 & - & + & - & + & - & - \\
5 & + & - & + & + & + & + \\
\hline
\end{tabular}

+ : present, -: absent

*Absent due to the inability to maintain a standing position

Table 3. Autonomic Tests.

\begin{tabular}{|c|c|c|c|c|c|c|c|c|c|c|c|}
\hline \multirow[b]{2}{*}{ Case } & \multirow[b]{2}{*}{$\begin{array}{c}\text { CVR-R } \\
(\%)\end{array}$} & \multirow[b]{2}{*}{$\begin{array}{l}\text { Valsalva } \\
\text { ratio }\end{array}$} & \multirow[b]{2}{*}{$\begin{array}{c}\text { Valsalva } \\
\text { test } \\
(\mathrm{mmHg})\end{array}$} & \multicolumn{4}{|c|}{ Heat-up tilt test } & \multirow[b]{2}{*}{$\begin{array}{c}\text { NA } \\
\text { infusion } \\
(\mathrm{mmHg})\end{array}$} & \multicolumn{3}{|c|}{ Myocardial MIBG scintigraphy } \\
\hline & & & & $\begin{array}{c}\mathrm{sBP} \\
(\mathrm{mmHg})\end{array}$ & $\begin{array}{c}\mathrm{dBP} \\
(\mathrm{mmHg})\end{array}$ & $\begin{array}{c}\mathrm{HR} \\
\text { (beats/ } \\
\text { min) }\end{array}$ & $\begin{array}{l}\text { TPR change } \\
\text { at } 60^{\circ} \text { from } \\
\text { baseline }(\%)\end{array}$ & & $\begin{array}{l}\text { Early } \\
\text { H/M } \\
\text { ratio }\end{array}$ & $\begin{array}{l}\text { Delay } \\
\mathrm{H} / \mathrm{M} \\
\text { ratio }\end{array}$ & $\begin{array}{c}\text { Wash out } \\
\text { rate } \\
(\%)\end{array}$ \\
\hline 1 & 0.71 & 1.00 & -7 & -47 & -38 & -1 & -54.9 & ND & 1.48 & 1.22 & 65.6 \\
\hline 2 & 0.95 & 0.94 & -2 & -73 & -50 & +32 & ND & +21 & 1.99 & 1.70 & 41.0 \\
\hline 3 & 1.03 & 1.03 & +15 & -23 & -29 & +10 & -41.5 & +30 & 1.86 & 1.27 & 72.4 \\
\hline 4 & 1.16 & 0.90 & -4 & -7 & 0 & +19 & -25.9 & +13 & 2.30 & 1.55 & 72.7 \\
\hline 5 & 0.68 & 1.00 & -3 & -23 & -21 & +6 & -8.2 & +29 & ND & ND & ND \\
\hline
\end{tabular}

CVR-R: coefficient of variation of R-R intervals, H/M: heart-to-mediastinum, dBP: diastolic blood pressure, HR: heart rate, MIBG: (123)I-metaiodobenzylguanidine, NA: noradrenaline, ND: not determined, sBP: systolic blood pressure, TPR: total peripheral resistance

The normal control values for CVR-R, Valsalva ratio, Valsalva test, sBP change, TPR change, NA infusion, early H/M ratio, delay HM ratio, and washout rate are $>1.41 \%, \geq 1.29,>0 \mathrm{mmHg},<20 \mathrm{mmHg},>0 \%, \leq 20 \mathrm{mmHg}, \geq 2.2, \geq 2.2$, and $\leq 34 \%$, respectively (14).

ance cardiography, and the average of the last 30 seconds at baseline, the fifth minute of the $20^{\circ}, 40^{\circ}$, and $60^{\circ}$ tilts, and the third minute after the return to the supine position were used for the analysis. Control values for impedance cardiography were obtained from 24 normal healthy subjects over 50 years of age (mean \pm standard deviation: $63.9 \pm 8.0$ years old) (14).

To determine the denervation supersensitivity of the resistance vessels to norepinephrine, the systolic blood pressure response to low-dose norepinephrine was assessed (16). A diluted norepinephrine solution was administered intravenously for 3 minutes at a rate of $3 \mu \mathrm{g} / \mathrm{min}$, and the increase in the systolic blood pressure, representing denervation supersensitivity, was assessed. During testing, the condition of each subject was continuously monitored by electrocardiogram, and blood pressure was measured every minute using a mercury sphygmomanometer placed on the upper arm opposite to that used for norepinephrine infusion.

\section{MIBG scintigraphy}

Myocardial MIBG scintigraphy was performed on a different day within one week of the aforementioned autonomic function tests, as described previously $(14,21)$. None of the patients were taking drugs known to affect the MIBG uptake, such as calcium channel blockers or tricyclic antidepressants. MIBG (111 mBq) was injected intravenously. Early images were obtained 15 minutes after the injection, and delayed images were obtained after 3 hours. Regions of interest included the whole heart and the mediastinum in the anterior projection, and the MIBG heart-to-mediastinum (H/ M) ratio was also calculated. MIBG imaging was standardized using a calibration phantom method.

\section{Results}

\section{Patient characteristics}

The initial manifestation of amyloidosis consisted of numbness in the limbs in Patients 1 (Val94Gly), 2 (Val71Ala), and 3 (Pro24Ser). In these patients, only symptoms resulting from neuropathy were reported at the time of the examination, although thickening of the interventricular septum and elevation of plasma B-type natriuretic peptide was detected in Patients 1 and 3 (Table 1). Cardiomyopathy was predominant in Patient 4 (Thr60Ala), and antidiuretic agents were initiated one year before the examination, after which only mild numbness in the toes was reported as symptoms attributable to neuropathy in this patient. The initial manifestation of vitreous opacities due to amyloidosis in Patient 5 (Tyr114Cys) appeared seven years before the autonomic tests. This patient was diagnosed with oculopleptomeningeal-type ATTRm amyloidosis. All patients reported some symptoms that were attributable to autonomic dysfunctions at the time of the autonomic tests (Table 2). All patients who were able to maintain a standing position reported some degree of orthostatic symptoms, and one (Patient 5) 
had a history of syncope. Another patient (Patient 2) did not complain of any orthostatic symptoms because this patient could not maintain a standing position due to weakness in the lower limbs.

\section{Autonomic tests}

All but one patient (Patient 4) with predominant cardiomyopathy manifested orthostatic hypotension, which is defined as a reduction in the systolic blood pressure of at least $20 \mathrm{mmHg}$ in the $60^{\circ}$ position during the head-up tilt test (Table 3). The CVR-R and Valsalva ratio were abnormal in all patients, suggesting the presence of cardiac parasympathetic dysfunctions. An overshoot of systolic blood pressure in the Valsalva test was not observed in four patients, indicating impaired cardiac sympathetic functions in these patients. Myocardial MIBG scintigraphy also indicated cardiac sympathetic denervation in all of the examined patients. The MIBG $\mathrm{H} / \mathrm{M}$ ratio tended to be lower in late images than in early images.

The total peripheral resistance at $60^{\circ}$ tilt was increased compared with the baseline levels in all normal subjects (14) but was lower than at baseline in all examined patients. The absence of an increase in the total peripheral resistance in these patients suggests an impaired peripheral vasoconstrictor response to orthostatic stress due to denervation of efferent sympathetic nerves $(18,20)$. Figure shows the sequential changes over time in the systolic blood pressure, diastolic blood pressure, heart rate, and total peripheral resistance at the fifth minute of the $20^{\circ}, 40^{\circ}$, and $60^{\circ}$ tilts, as measured by impedance cardiography. In normal subjects, the systolic blood pressure tended to be preserved during the head-up tilt test but was significantly decreased at the fifth minute of the $60^{\circ}$ tilts in Patients 1, 3, and 5 (Figure A). Recovery from this drop in the blood pressure was observed after these patients returned to the supine position. The pattern of sequential changes in the diastolic blood pressure was similar to that observed for the systolic blood pressure in both ATTRm amyloidosis patients and normal subjects (Figure B). Regarding the change in the heart rate, an increase was observed during orthostatic stress in Patients 3 to 5 (Figure C) similar to that in normal subjects. However, the heart rate did not increase in Patient 1, who manifested the most prominent orthostatic hypotension. In contrast, the pattern of change in total peripheral resistance in our patients differed from that observed in normal subjects, even in $\mathrm{Pa}-$ tient 4, who did not have significant orthostatic hypotension (Figure D).

An infusion of low-dose noradrenaline induced a rise in the systolic blood pressure in all examined patients. Three of these patients were considered to have supersensitivity of the resistance vessels due to denervation of peripheral sympathetic efferent fibres, because they showed an increase in the systolic blood pressure exceeding $20 \mathrm{mmHg}$ (22). The systolic blood pressure increased by less than $20 \mathrm{mmHg}$ in 1 patient with predominant cardiomyopathy but no significant orthostatic hypotension (Patient 4).

\section{Discussion}

Autonomic dysfunctions are considered characteristic of ATTRm amyloidosis because they have been found to be prominent from the initial phase of neuropathy, particularly in conventional early-onset Val30Met cases from endemic foci of Portugal and Japan $(23,24)$. In contrast, autonomic symptoms are less conspicuous, particularly in the early disease phase, in late-onset Val30Met cases from non-endemic areas $(8,25)$. Evaluating the autonomic function is important in ATTRm amyloidosis for making an early diagnosis $(10,26)$, monitoring the status of liver transplantation $(13,27-29)$, and predicting the prognosis $(2,30)$. Although a correlation between the sudomotor innervation and functional status has been reported in Ala97Ser patients in Taiwan (2), information regarding the spectrum and severity of autonomic dysfunction in non-Val30Met patients is lacking.

Large-scale studies have suggested that clinically significant autonomic dysfunctions are prevalent even in patients with non-Val30Met mutations $(3,5,7)$. Most reports regarding the postmortem examination of non-Val30Met ATTRm amyloidosis have emphasized amyloid deposition in the thoracic sympathetic ganglia (31-34). According to a detailed postmortem examination of the peripheral nervous system in a recipient who died eight years after sequential liver transplantation from a ATTRm amyloidosis donor with a Tyr114Cys mutation, amyloid deposition was found only in the thoracic sympathetic ganglia and median nerve at the level of the carpal tunnel (35). These reports indicate that autonomic ganglia are susceptible sites of amyloid deposition, even in non-Val30Met ATTRm amyloidosis patients. However, a preserved autonomic function despite significant somatic sensory and motor neuropathy was reported in a patient with an Ala97Gly mutation (6). Thus, autonomic dysfunctions in non-Val30Met ATTRm amyloidosis patients may be diverse and have not yet been fully elucidated, particularly in clinical practice.

In this study, we systematically assessed the cardiac and peripheral vasomotor autonomic functions in non-Val30Met ATTRm amyloidosis patients. Although the number of examined patients was few, three major phenotypes of ATTRm amyloidosis (i.e. neuropathy, cardiomyopathy, and oculoleptomeningeal involvement) were included. Although one patient with predominant cardiomyopathy did not manifest orthostatic hypotension during the head-up tilt test, other autonomic tests indicated the presence of widespread cardiac and peripheral vasomotor autonomic dysfunctions in this patient. The profile of cardiovascular autonomic dysfunctions therefore seemed to be similar in our patients regardless of their phenotypes, suggesting a common pathology of autonomic involvement in non-Val30Met ATTRm amyloidosis.

In contrast to the cardiac autonomic functions, the peripheral vasomotor functions have rarely been examined, even in Val30Met patients $(11,12,14,36)$. In the present study, the 
A

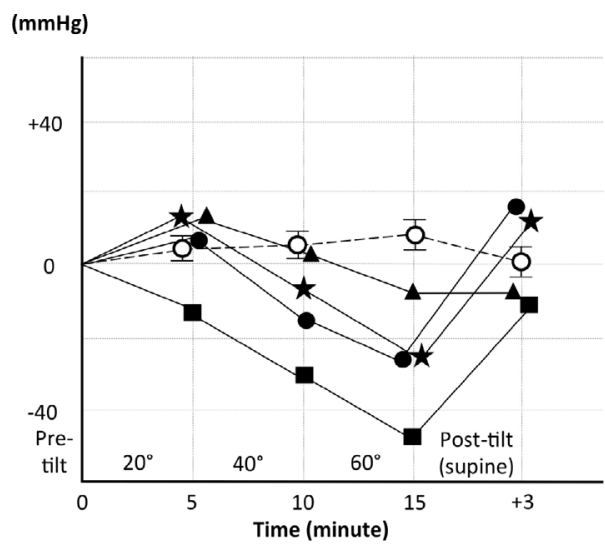

C

(beats/minute)

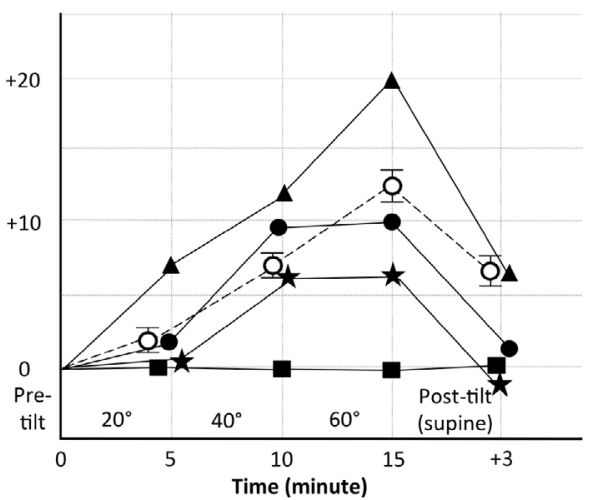

B

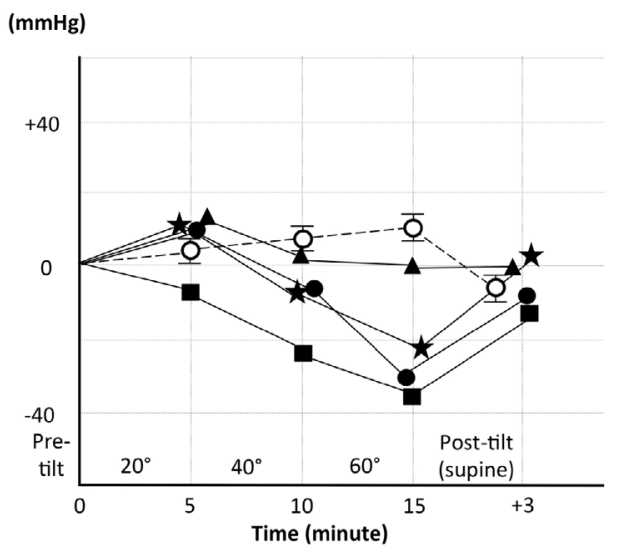

D

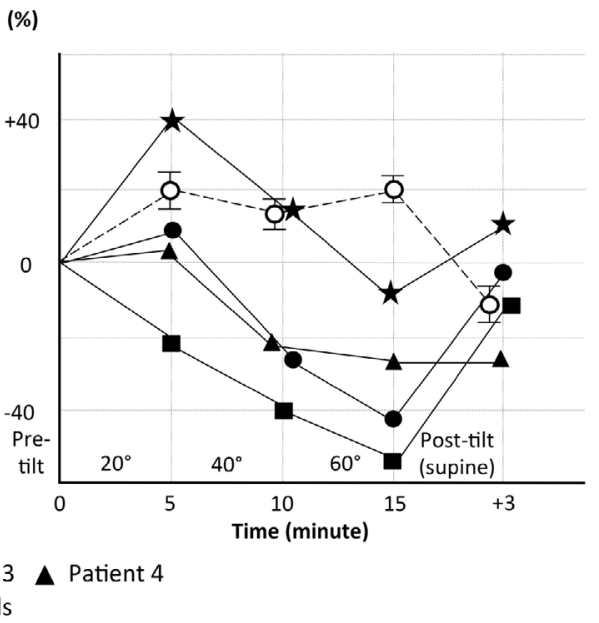

Figure. Sequential changes over time in the systolic blood pressure (A), diastolic blood pressure (B), heart rate $(C)$, and total peripheral resistance $(D)$ at the fifth minute of the $20^{\circ}, 40^{\circ}$, and $60^{\circ}$ tilts, as measured by impedance cardiography. (A) In normal subjects, the systolic blood pressure tended to be preserved during the head-up tilt test but decreased significantly at the fifth minute of the $60^{\circ}$ tilt in Patients 1, 3, and 5. Recovery from the drop in the blood pressure was observed in these patients after returning to the supine position. (B) The pattern of sequential changes in the diastolic blood pressure was similar to that in the systolic blood pressure in both ATTRm amyloidosis patients and normal subjects. (C) An increase in the heart rate was observed during orthostatic stress in Patients 3 to 5; this pattern was similar to that in normal subjects. However, the heart rate did not increase in Patient 1, who manifested the most prominent orthostatic hypotension. (D) The pattern of change in total peripheral resistance in ATTRm amyloidosis patients differed from that observed in normal subjects, even in Patient 4, who did not have significant orthostatic hypotension. Control values were obtained from 24 normal healthy subjects $63.9 \pm 8.0$ (mean SD) years of age (14). The error bars represent the standard error of the mean.

total peripheral resistance at $60^{\circ}$ tilt did not increase from the baseline values in any of the examined patients, and an infusion of low-dose noradrenaline induced a significant increase in the systolic blood pressure except for in a patient with mild neuropathy. These findings indicate that impairment of the peripheral sympathetic vasoconstrictor function was prevalent in our patients. However, the presence of supersensitivity to low-dose noradrenaline suggests that the vasoconstrictor function of the resistance vessels was preserved even in the patient with advanced neuropathy, indicating the usefulness of alpha-adrenoceptor agonists in the management of orthostatic hypotension in ATTRm amyloidosis patients with non-Val30Met mutations.

The authors state that they have no Conflict of Interest (COI).

\section{Financial Support}

This work was supported by grants from the Ministry of Health, Labor and Welfare (Research on rare and intractable diseases, H29-022) and the Ministry of Education, Culture, Sports, Science and Technology (17K09777) of Japan. 


\section{References}

1. Sekijima Y, Ueda M, Koike H, Misawa S, Ishii T, Ando Y. Diagnosis and management of transthyretin familial amyloid polyneuropathy in Japan: red-flag symptom clusters and treatment algorithm. Orphanet J Rare Dis 13: 6, 2018.

2. Chao CC, Huang CM, Chiang HH, et al. Sudomotor innervation in transthyretin amyloid neuropathy: pathology and functional correlates. Ann Neurol 78: 272-283, 2015.

3. Carr AS, Pelayo-Negro AL, Evans MR, et al. A study of the neuropathy associated with transthyretin amyloidosis (ATTR) in the UK. J Neurol Neurosurg Psychiatry 87: 620-627, 2016.

4. Durmuş-Tekçe H, Matur Z, Mert Atmaca M, et al. Genotypic and phenotypic presentation of transthyretin-related familial amyloid polyneuropathy (TTR-FAP) in Turkey. Neuromuscul Disord 26: 441-446, 2016.

5. Yamashita T, Ueda M, Misumi Y, et al. Genetic and clinical characteristics of hereditary transthyretin amyloidosis in endemic and non-endemic areas: experience from a single-referral center in Japan. J Neurol 265: 134-140, 2018.

6. Yasuda T, Sobue G, Doyu M, et al. Familial amyloidotic polyneuropathy with late-onset and well-preserved autonomic function: a Japanese kindred with novel mutant transthyretin (Ala97 to Gly). J Neurol Sci 121: 97-102, 1994.

7. Mariani LL, Lozeron P, Théaudin M, et al. Genotype-phenotype correlation and course of transthyretin familial amyloid polyneuropathies in France. Ann Neurol 78: 901-916, 2015.

8. Koike H, Tanaka F, Hashimoto R, et al. Natural history of transthyretin Val30Met familial amyloid polyneuropathy: analysis of late-onset cases from non-endemic areas. J Neurol Neurosurg Psychiatry 83: 152-158, 2012.

9. Niklasson U, Olofsson BO, Bjerle P. Autonomic neuropathy in familial amyloidotic polyneuropathy. A clinical study based on heart rate variability. Acta Neurol Scand 79: 182-187, 1989.

10. Ando Y, Obayashi K, Tanaka Y, et al. Radiolabelled metaiodobenzylguanidine in assessment of autonomic dysfunction. Lancet 343: 984-985, 1994.

11. Obayashi K, Ando Y, Nakamura M, et al. Endothelium-dependent vasodilatation in patients with familial amyloidotic polyneuropathy. Muscle Nerve 23: 1084-1088, 2000.

12. Obayashi K, Ando Y, Nakamura M, et al. Near-infrared spectrophotoscopy of finger venules in assessment of autonomic dysfunction. Neurology 63: 164-166, 2004.

13. Hörnsten R, Suhr OB, Jensen SM, Wiklund U. Outcome of heart rate variability and ventricular late potentials after liver transplantation for familial amyloidotic polyneuropathy. Amyloid 15: 187195, 2008.

14. Koike H, Nakamura T, Hashizume A, et al. Cardiac and peripheral vasomotor autonomic functions in late-onset transthyretin Val30 Met familial amyloid polyneuropathy. J Neurol 264: 2293-2302, 2017.

15. van Swieten JC, Koudstaal PJ, Visser MC, Schouten HJ, van Gijn $\mathrm{J}$. Interobserver agreement for the assessment of handicap in stroke patients. Stroke 19: 604-607, 1988.

16. Nakamura T, Hirayama M, Hara T, Hama T, Watanabe H, Sobue G. Does cardiovascular autonomic dysfunction contribute to fatigue in Parkinson's disease? Mov Disord 26: 1869-1874, 2011.

17. Nakamura T, Suzuki M, Okada A, et al. Association of leptin with orthostatic blood pressure changes in Parkinson's disease. Mov Disord 31: 1417-1421, 2016.

18. Suzuki J, Nakamura T, Hirayama $M$, et al. Impaired peripheral vasoconstrictor response to orthostatic stress in patients with multiple system atrophy. Parkinsonism Relat Disord 21: 917-922,
2015.

19. Suzuki M, Nakamura T, Hirayama M, Ueda M, Katsuno M, Sobue G. Cardiac parasympathetic dysfunction in the early phase of Parkinson's disease. J Neurol 264: 333-340, 2017.

20. Nakamura T, Hirayama M, Hara T, et al. Role of cardiac sympathetic nerves in preventing orthostatic hypotension in Parkinson's disease. Parkinsonism Relat Disord 20: 409-414, 2014.

21. Nakamura T, Hirayama M, Yamashita F, et al. Lowered cardiac sympathetic nerve performance in response to exercise in Parkinson's disease. Mov Disord 25: 1183-1189, 2010.

22. Niimi $Y$, Ieda $T$, Hirayama $M$, et al. Clinical and physiological characteristics of autonomic failure with Parkinson's disease. Clin Auton Res 9: 139-144, 1999.

23. Koike H, Misu K, Ikeda S, et al. Type I (transthyretin Met30) familial amyloid polyneuropathy in Japan: early- vs late-onset form. Arch Neurol 59: 1771-1776, 2002.

24. Ando Y, Nakamura M, Araki S. Transthyretin-related familial amyloidotic polyneuropathy. Arch Neurol 62: 1057-1062, 2005.

25. Koike H, Misu K, Sugiura M, et al. Pathology of early- vs lateonset TTR Met30 familial amyloid polyneuropathy. Neurology $\mathbf{6 3}$ : 129-138, 2004.

26. Castro J, Miranda B, Castro I, de Carvalho M, Conceição I. The diagnostic accuracy of Sudoscan in transthyretin familial amyloid polyneuropathy. Clin Neurophysiol 127: 2222-2227, 2016.

27. Ando Y, Tanaka Y, Ando E, et al. Effect of liver transplantation on autonomic dysfunction in familial amyloidotic polyneuropathy type I. Lancet 345: 195-196, 1995.

28. Adams D, Samuel D, Goulon-Goeau C, et al. The course and prognostic factors of familial amyloid polyneuropathy after liver transplantation. Brain 123: 1495-1504, 2000.

29. Delahaye N, Rouzet F, Sarda L, et al. Impact of liver transplantation on cardiac autonomic denervation in familial amyloid polyneuropathy. Medicine (Baltimore) 85: 229-238, 2006.

30. Coutinho MC, Cortez-Dias N, Cantinho G, et al. Reduced myocardial 123-iodine metaiodobenzylguanidine uptake: a prognostic marker in familial amyloid polyneuropathy. Circ Cardiovasc Imaging 6: 627-636, 2013.

31. Takahashi N, Ueno S, Uemichi T, Fujimura H, Yorifuji S, Tarui S. Amyloid polyneuropathy with transthyretin Arg50 in a Japanese case from Osaka. J Neurol Sci 112: 58-64, 1992.

32. Yazaki M, Take YI, Katoh M, Ikeda SI. Postmortem findings in two familial amyloidosis patients with transthyretin variant Asp38 Ala. Amyloid 7: 270-277, 2000.

33. Nagasaka $\mathrm{T}$, Togashi $\mathrm{S}$, Watanabe $\mathrm{H}$, et al. Clinical and histopathological features of progressive-type familial amyloidotic polyneuropathy with TTR Lys54. J Neurol Sci 276: 88-94, 2009.

34. Uehara T, Kakuda K, Sumi-Akamaru H, Yamauchi A, Mochizuki H, Naka T. An autopsy case of leptomeningeal amyloidosis associated with transthyretin Gly47Arg mutation. Rinsho Shinkeigaku 56: 777-780, 2016 (in Japanese, Abstract in English).

35. Koike H, Kiuchi T, Iijima M, et al. Systemic but asymptomatic transthyretin amyloidosis 8 years after domino liver transplantation. J Neurol Neurosurg Psychiatry 82: 1287-1290, 2011.

36. Suzuki T, Higa S, Tsuge I, et al. Effect of infused L-threo-3,4dihydroxyphenylserine on adrenergic activity in patients with familial amyloid polyneuropathy. Eur J Clin Pharmacol 17: 429-435, 1980.

The Internal Medicine is an Open Access journal distributed under the Creative Commons Attribution-NonCommercial-NoDerivatives 4.0 International License. To view the details of this license, please visit (https://creativecommons.org/licenses/ by-nc-nd/4.0/).

(C) 2018 The Japanese Society of Internal Medicine Intern Med 57: 3365-3370, 2018 